\title{
Evaluation of the Skin Irritation and Sensitization Potential of the Cussons Baby Sensicare Skin Range of Products in Healthy Volunteers
}

\author{
Yullya S. Mulyanti, Yuliarni, Busarin Kasemchainan, Partha P. Mitra, Paul Evans, \\ Haryono Hartono
}

R\&D Formulation, PZ Cussons Indonesia, Jakarta, Indonesia

Email: YullyaSyahri.Mulyanti@pzcussons.com

How to cite this paper: Mulyanti, Y.S., Yuliarni, Kasemchainan, B., Mitra, P.P., Evans, P. and Hartono, H. (2019) Evaluation of the Skin Irritation and Sensitization Potential of the Cussons Baby Sensicare Skin Range of Products in Healthy Volunteers. Journal of Cosmetics, Dermatological Sciences and Applications, 9, 207-215.

https://doi.org/10.4236/jcdsa.2019.93017

Received: May 23, 2019

Accepted: August 17, 2019

Published: August 20, 2019

Copyright $\odot 2019$ by author(s) and Scientific Research Publishing Inc. This work is licensed under the Creative Commons Attribution International License (CC BY 4.0).

http://creativecommons.org/licenses/by/4.0/

\begin{abstract}
Introduction: The Cussons Baby Sensicare Range is a newly developed set of products specially formulated for newborn, sensitive and eczema prone skin. As such, these products need to be tested to evaluate their skin irritation and sensitization potential before use. The products were evaluated with two separate tests. The first test was conducted in a single-center, within-subject comparison using assessor-blind, randomised human skin irritation patch test (48 hour/96 hour exposure) and conducted on healthy adults with sensitive, atopic skin. The second test was conducted in a single-center, controlled (sterile water), within subject using human repeat-insult patch tests (HRIPTs) and conducted on healthy female Indonesian and Asian adult female subjects, with sensitive skin. The sensitization potential of each product was determined from International Contact Dermatitis Research Group (ICDRG) scores at 30 minutes, 24 hours, 48 hours and 72 hours after patch removal. Skin irritation tests show that all products were significantly lower than the positive control sodium lauryl sulphate (SLS) $(\mathrm{p}<0.05)$ but not significantly different to the negative control (sterile water) in terms of irritation scores at the respective time points. HRIPTs results show that Cussons Baby Sensicare Range was non-sensitizing. As such, it can be concluded that the Cussons Baby Sensicare Range tested is well tolerated on skin and has low skin irritation and sensitization potential. Thus, they can be considered hypoallergenic on sensitive skin and suitable for eczema prone skin.
\end{abstract}

\section{Keywords}

Cussons Baby Sensicare, Skin Irritation, Skin Sensitization, Hypoallergenic, 
HRIPT, Atopic Skin Care, Eczema Prone Skin Care

\section{Introduction}

Contact sensitization is a process whereby the host (through prior skin exposure) acquires a specific, increase sensitivity (reactivity) to a substance upon subsequent exposure. Whereas reactions may be minimal or absent upon the first contact, the skin responds to subsequent applications in a heightened manner. The reaction may range in severity from a minor annoyance of transient redness and itching, to a severe, widespread and possibly disabling eczematous eruption. It is important that new cosmetic products are tested to evaluate their skin irritation and sensitization potential.

The Cussons Baby Sensicare Range (PZ Cussons, Indonesia) is a new specially developed range of products for newborn, sensitive and eczema prone skin. Baby skin differs from adult skin and requires special care [1] [2]. The products are based on a Triple Protection Complex consisting of avena sativa (oat) extract, olea Europaea (olive) fruit oil and ceramides; ingredients selected for their dermocosmetic properties (moisturization, barrier protection, anti-inflammatory, antioxidant and soothing effects). Oats have been used for a long time to alleviate itching and irritation [3] and avena sativa has been shown to have preventive effects on skin irritation in a SLS model [4]. Olive oil's composition is similar to that of sebum which makes it particularly able to protect the skin [5]. Ceramide 3 has been shown to have a protecting effect against surfactant-induced dermatitis [6]. In order to determine the hypoallergenicity and skin irritation potential of the Cussons Baby Sensicare range of products a human repeat insult patch test (HRIPT) and human skin irritation patch test were conducted in adult volunteers.

\section{Methods}

\subsection{Test Products}

Commercially available product provided by PZ Cussons Indonesia was investigated in these studies. Cussons Baby Sensicare Gentle Hair and Body Wash is a surfactant base with Dermasoft ${ }^{\mathrm{TM}}$ Complex and Argania spinosa (Argan) kernal oil. The Cussons Baby Sensicare 24 hr Daily Moisturizing Lotion and Cussons Baby Sensicare Intensive Soothing Cream are oil in water emulsion with Dermasoft ${ }^{\mathrm{TM}}$ Complex and Butyrospermum parkii (Shea) Butter. Detail of ingredients list of Cussons Baby Sensicare Range provided in Table 1.

\subsection{Skin Irritation Potential (48/96 h Single Patch Test)}

This was a single-centre, within-subject comparison, assessor blinded, randomised study conducted by Alba Science Ltd in 26 healthy volunteers, male and female aged 18 to 70 who had self-assessed sensitive, atopic skin (assessed by completion of a questionnaire). 
Table 1. Ingredients list cussons baby sensicare.

\begin{tabular}{|c|c|}
\hline Product & Ingredients List \\
\hline $\begin{array}{l}\text { Cussons Baby } \\
\text { Sensicare Gentle } \\
\text { Hair and Body } \\
\text { Wash }\end{array}$ & $\begin{array}{l}\text { Aqua, Cocamidopropyl Betaine, Sodium Laureth Sulfate, PEG-6 Caprylic/Capric } \\
\text { Glycerides, Glycerin, Sodium Benzoate, Parfum, Lactic Acid, PEG-200 } \\
\text { Hydrogenated Glyceryl Palmate, PEG-7 Glyceryl Cocoate, Allantoin, } \\
\text { Tetrasodium Glutamate Diacetate, Avena Sativa (Oat) Kernel Extract, } \\
\text { Potassium Sorbate, Sorbic Acid, Polyquaternium-7, Tocopheryl Acetate, } \\
\text { Sodium Hydroxide, Argania Spinosa Kernel Oil, Olea europaea (Olive) Fruit } \\
\text { Oil, Ceramide NP, Ceramide AP, Ceramide EOP, Phytosphingosine, } \\
\text { Cholesterol, Sodium Lauroyl Lactylate, Carbomer, Xanthan Gum. }\end{array}$ \\
\hline $\begin{array}{l}\text { Cussons Baby } \\
\text { Sensicare } 24 \mathrm{hr}\end{array}$ & $\begin{array}{l}\text { Aqua, Glycerin, Caprylic/Capric Triglycerides, Cetyl Alcohol, Ethylhexyl } \\
\text { Palmitate, Glyceril Stearate, Cetearyl Alcohol, Phenoxyethanol, Dimethicone, } \\
\text { Myristil Myristate, Sodium Benzoate, Carbomer, Allantoin, Butyrospermum } \\
\text { Parkii (Shea) Butter, Ceteareth-20, Fragrance, Sorbitan Caprylate, Tetrasodium }\end{array}$ \\
\hline $\begin{array}{l}\text { Daily Moisturizin } \\
\text { Lotion }\end{array}$ & $\begin{array}{l}\text { Glutamate Diacetate, Olea Europaea (Olive) Fruit Oil, Tocopheryl Acetate, } \\
\text { Sodium Hydroxide, Avena Sativa (Oat) Kernel Extract, Potassium Sorbate, } \\
\text { Sorbic Acid, Ceramide NP, Ceramide AP, Ceramide EOP, Phytosphingosine, } \\
\text { Cholesterol, Sodium Lauroyl Lactylate, Xanthan Gum. }\end{array}$ \\
\hline $\begin{array}{l}\text { Cussons Baby } \\
\text { Sensicare Intensive } \\
\text { Soothing Cream }\end{array}$ & $\begin{array}{l}\text { Aqua, Helianthus annus (sunflower) seed Oil, Butyrospermum Parkii (Shea) } \\
\text { Butter, Cera alba, Cetearyl Alcohol, Dimethicone, Glycerin, Glyceryl Stearate, } \\
\text { PEG-100 Stearate, Phenoxyethanol, Carbomer, Sodium Benzoate, Fragrance, } \\
\text { Sorbitan Caprylate, Xanthan gum, Allantoin, Olea Europaea (Olive) Fruit Oil, } \\
\text { Tocopheryl Acetate, Sodium Hydroxide, Avena Sativa (Oat) Kernel Extract, } \\
\text { Potassium Sorbate, Sorbic Acid, Tocopherol, Ceramide NP, Ceramide AP, } \\
\text { Ceramide EOP, Phytosphingosine, Cholesterol, Sodium Lauroyl Lactylate, } \\
\text { Xanthan Gum. }\end{array}$ \\
\hline
\end{tabular}

The Cussons Baby Sensicare Gentle Hair \& Body Wash was assessed over 48-hour exposure with 2 consecutive 23-hour patch applications of $2.0 \%$ concentration. Cussons Baby Sensicare 24 hours Daily Moisturizing Lotion and the Cussons Baby Sensicare Intensive Soothing Cream were assessed over 96-hour exposure with 4 consecutive 23 -hour patch applications. SLS $(0.3 \% \mathrm{w} / \mathrm{v})$ and sterile water were included as controls.

The application area for the test and control products was the upper, outer arms. A randomised product application schedule was generated for each subject to randomly allocate each product to an application site. The order of products in the patch schedule was randomised to eliminate position and order bias.

Approximately $20 \mu \mathrm{l}$ of each product and control was applied to the skin under an occlusive patch (Finn Chamber $8 \mathrm{~mm}$ ). Skin markers marked either end of the Finn Chamber to allow exact relocation to the test areas at subsequent applications. Approximately 23 hours after application the subjects removed their patch and washed the test sites to remove residual test and control material. The test sites were assessed approximately 1 hour later by a trained assessor, following the scoring system detailed in Table 2. After assessment, an identical patch was reapplied to the same area for a further period of approximately 23 hours. The test and control materials were reapplied to the same sites as before, following assessment. Any test or control material which elicited erythema or dryness with a score of 5 or more was not reapplied. Any test or control material which elicited a palpable response was not reapplied. 
Table 2. Scoring scale wet used during study skin irritation potential.

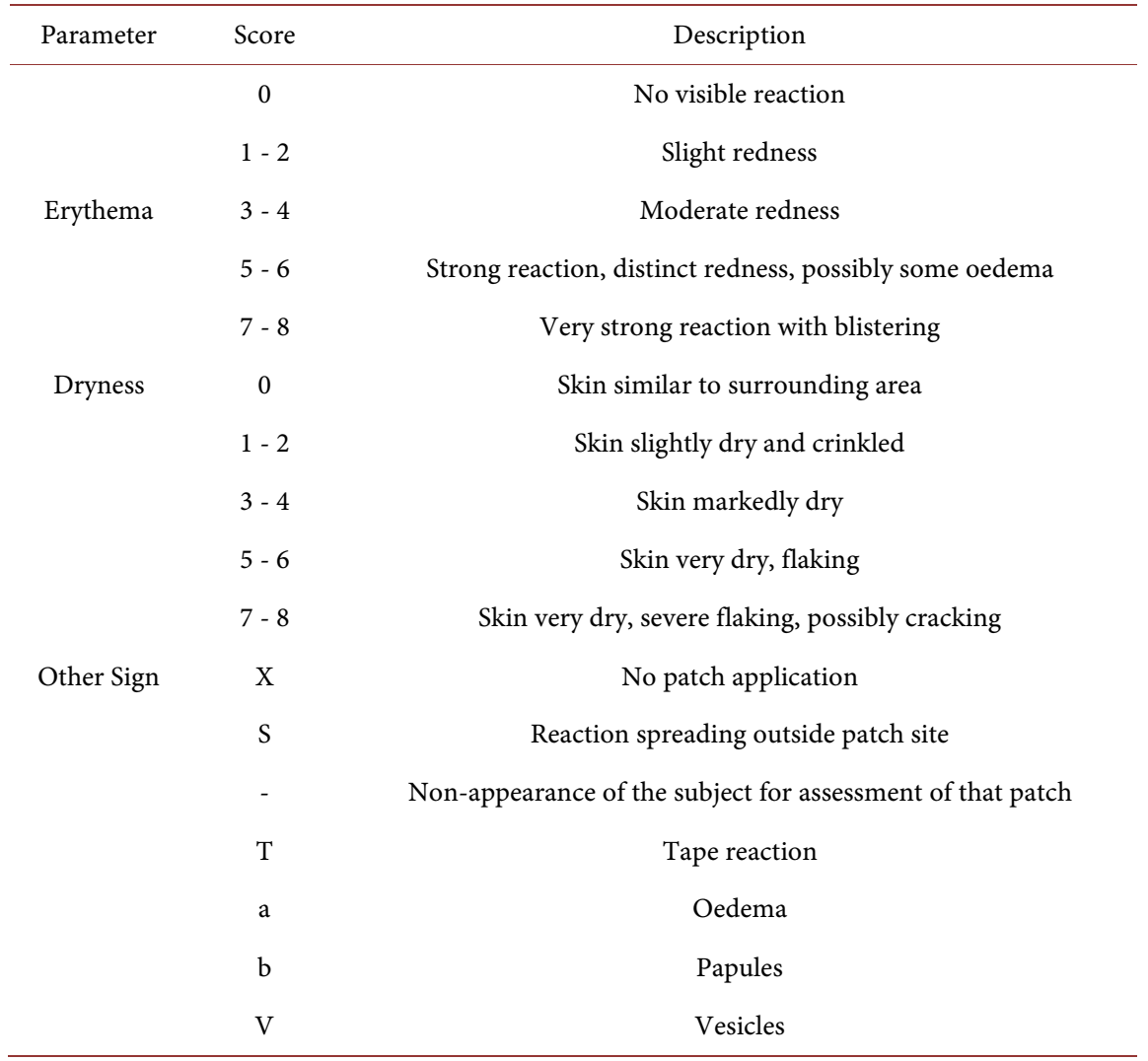

For the $48 \mathrm{~h}$ test materials, treatment was over 3 consecutive days, commencing on Day 1 when the test materials were applied as described. The test materials were applied on Days 1 and 2. Skin assessments were on Days 2 and 3. The paediatric consultant was present for skin assessments on Day 3.

For the $96 \mathrm{~h}$ test materials, treatment was over 5 consecutive days, commencing on Day 1 when the test materials were applied as described. The test materials were applied on Days 1, 2, 3 and 4. Skin assessments were on Days 2, 3, 4 and 5. The paediatric consultant was present for skin assessments on Day 5.

Erythema, Dryness and Irritation scores are ordinal categorical measurements taken repeatedly on volunteers, so multinomial models coupled with Generalised Estimating Equations (GEEs) were fitted. This method accommodates both the ordinal categorical nature of the response scores and potential correlated errors within subjects. Only the responses at $48 \mathrm{~h}$ and $96 \mathrm{~h}$ were considered.

Multiple-comparison adjustments were made to significance levels, where appropriate, to maintain a nominal family-level type I error rate of 5\%. All analysis was conducted in SASV 9.4 and RV 3.2.

\subsection{Skin Sensitization Potential (Human Repeat Insult Patch Test, HRIPTs)}

One hundred (100) healthy female Indonesian and Asian subjects, aged 18 - 55 years old with sensitive skin and uniform pigmentation on the test area were re- 
quired for study entry. Selection of subjects with sensitive skin was based on a positive skin reaction to a $1 \%$ closed patch test with sodium lauryl sulphate (SLS) for 24 hours.

The studies were controlled, within subject, human repeat-insult patch tests (HRIPT) conducted by Assertra Inno Medikos Dermatology Laboratory in Indonesia. Each product (about $20 \mu \mathrm{l}$ ) was applied under an occlusive patch (Finn Chamber $\left.8 \mathrm{~mm}\left(50 \mathrm{~mm}^{2}\right)\right)$ to intact skin on the back of each volunteer every other day for 3 weeks (Induction Phase). The subjects then had a 2 week Rest Phase before the Challenge Phase when subjects were patched again for 24 hours to a previously untreated skin site. An overview of the product application in the RIPTs is provided in Table 3.

Table 3. Overview of product application in human repeat-insult patch tests (HRIPTs).

\begin{tabular}{cccc}
\hline Study & AIM KHCT 51801 & AIM KHCT 51803 & AIM KHCT 51805 \\
\hline Product & $\begin{array}{c}\text { Sensicare Gentle Hair \& } \\
\text { Body Wash }\end{array}$ & $\begin{array}{c}\text { Sensicare 24 Hours Daily } \\
\text { Moisturizing Body Lotion }\end{array}$ & Sensicare Intensive Cream \\
Induction Area & Left side back & Left side back & Left side back \\
Conc. Applied & $0.5 \%$ dilution & $100 \%$ & $100 \%$ \\
Challenge Phase & Right side back & Right side back & Right side back \\
Conc. Applied & $1 \%$ dilution & $100 \%$ & $100 \%$ \\
\hline
\end{tabular}

Thirty minutes after removal of each patch and prior to the next patch application during the Induction Phase, erythema, oedema, dryness and presence of vesicles were assessed and recorded by a Dermatologist according to the criteria detailed in Table 4. The Mean Cumulative Irritation Index (MCII) across the study population was calculated from these scores using the following formula:

Table 4. Criteria applied to assess the irritation potential during induction phase of Repeat-Insult patch test.

\begin{tabular}{|c|c|c|c|c|c|}
\hline \multirow{2}{*}{ Score } & \multirow{2}{*}{ Category } & \multicolumn{4}{|c|}{ Criteria: Description } \\
\hline & & Erythema & Oedema & Dryness & Vesicles \\
\hline 0.5 & Very Slight & $\begin{array}{l}\text { Very slight erythema (hardly visible): quite } \\
\text { pink colouration of one part of the tested area }\end{array}$ & $\begin{array}{c}\text { Very slight oedema } \\
\text { (palpable, hardly visible) }\end{array}$ & Slight dryness & $\begin{array}{l}\text { Papulae, or small vesicles } \\
\text { (less than about } 1 \mathrm{~mm} \text { in } \\
\text { diameter) }\end{array}$ \\
\hline 1 & Slight & $\begin{array}{c}\text { Slight erythema: quite pink colouration of the } \\
\text { complete tested area or rather visible in one } \\
\text { part of the tested area }\end{array}$ & $\begin{array}{l}\text { Slight oedema } \\
\text { (palpable and visible) }\end{array}$ & Clear dryness & $\begin{array}{l}\text { Vesicles } 1 \text { to } 2 \mathrm{~mm} \text { in } \\
\text { diameter }\end{array}$ \\
\hline 2 & Obvious & $\begin{array}{l}\text { Clear erythema: well defined erythema } \\
\text { covering all of the tested areas }\end{array}$ & $\begin{array}{l}\text { Clear oedema with or without } \\
\text { papule(s) or vesicle(s) }\end{array}$ & $\begin{array}{c}\text { Moderate } \\
\text { desquamation }\end{array}$ & Pustules \\
\hline 3 & Severe & $\begin{array}{l}\text { Severe erythema covering all of the tested area } \\
\text { or erythema diffusing outside the tested area }\end{array}$ & $\begin{array}{l}\text { Severe oedema (extended area } \\
\text { outside the tested area) with or } \\
\text { without vesicle(s) or blister(s) }\end{array}$ & $\begin{array}{c}\text { Severe } \\
\text { desquamation }\end{array}$ & Bullae with clear liquid \\
\hline
\end{tabular}


$\mathrm{MCII}=\left[\frac{\left(\frac{\sum \operatorname{Scores}\left(D_{1} \cdots D_{21}\right)}{\text { Number of reading }}\right) \operatorname{Sub1}+\cdots+\left(\frac{\sum \operatorname{Scores}\left(D_{1} \cdots D_{21}\right)(n-1) x^{2}}{\text { Number of reading }}\right) \operatorname{SubN}}{\text { Number of Subjects }(N)}\right]$

The irritating potential of each product during the Induction Phase was then classified according to MCII as detailed in Table 5.

Table 5. Irritating potential as determined by the mean cumulative irritation index.

\begin{tabular}{cc}
\hline MCII & Irritating Potential \\
\hline $0.0-0.08$ & Non irritating/negligible \\
$>0.08-0.16$ & Very slight irritation \\
$>0.16-0.50$ & Slightly irritating \\
$>0.50-1.00$ & Moderately irritating \\
$>1.00-1.60$ & Strongly irritating \\
$>1.60$ & Very strongly irritating \\
\hline
\end{tabular}

During the Challenge Phase, skin reactions were scored according to the International Contact Dermatitis Research Group (ICDRG) at 30 minutes, 24 hours, 48 hours and 72 hours after patch removal (Table 6). The sensitization potential of each product was determined from these scores.

Table 6. ICDRG criteria for assessing sensitization potential during challenge phase of repeat-insult patch test.

\begin{tabular}{ccc}
\hline Criterion & ICDRG Notation & Score \\
\hline No reaction & 0 & 0 \\
Doubtful reaction & \pm & 0.5 \\
Erythema and oedema & + & 1 \\
Erythema, oedema and vesicles & ++ & 2 \\
Severe reaction with blisters & +++ & 3 \\
\hline
\end{tabular}

ICDRG = International Contact Dermatitis Research Group.

\section{Results}

\subsection{Skin Irritation Potential}

Twenty-nine subjects with self-assessed sensitive, atopic skin were recruited for the study and 27 subjects were screened. Of these, 26 subjects participated in and completed the study (10 males and 16 females). The mean age of study participants was 39.4 years (range 19 - 63 years). The total means of irritation scores (erythema and dryness) are presented in Table 7 . All products were significantly lower than the positive control $(\mathrm{p}<0.05)$. The products were not significantly different from the negative control in terms of irritation scores at the respective time points. There were no adverse events reported during the study. All test products were well tolerated during the study. 
Table 7. ICDRG criteria for assessing sensitization potential during challenge phase of repeat-insult patch test.

\begin{tabular}{ccccc}
\hline \multirow{2}{*}{$\begin{array}{c}\text { Test } \\
\text { Period }\end{array}$} & Test Product & \multicolumn{2}{c}{ Total Mean (SD) Irritation Scores $(N=26)$} \\
\cline { 3 - 5 } & Test Product & \multicolumn{2}{c}{ Control Products } \\
\cline { 3 - 5 } 48 Hours & $\begin{array}{c}\text { Cussons Baby Sensicare Gentle Hair } \\
\text { \& Body Wash }\end{array}$ & $0.83(1.94)$ & $1.25(4.58)$ & $0.50(1.44)$ \\
& $\begin{array}{c}\text { Cussons Baby Sensicare 24 hours } \\
\text { Daily Moisturizing Lotion } \\
96 \text { Hours } \\
\text { Cussons Baby Sensicare Intensive } \\
\text { Soothing Cream }\end{array}$ & $0.08(0.68)$ & & \\
\cline { 3 - 5 } & $0.12(0.90)$ & & \\
\hline
\end{tabular}

SLS $=$ sodium lauryl sulphate.

\subsection{HRIPT}

One hundred and forty-five (145) subjects were evaluated with the $1 \%$ closed patch test with SLS. From these subjects one hundred and eleven (111) subjects were selected to enter the study, having confirmed sensitive skin. There were seven (7) dropouts and one hundred and four (104) subjects completed the study. The average age of study participants was 34.8 years (range 18 - 53 years).

The Cussons Baby Sensicare Gentle Hair and Body Wash was found to be slightly irritating during the Induction Phase of the RIPT $(\mathrm{MCII}=0.183$ ) and non-sensitizing (reaction was only very slight erythema in 23/104 subjects with no persist oedema or infiltration reactions noted). The Cussons Baby Sensicare 24 hours Daily Moisturizing Lotion was found to be very slightly irritating during the Induction Phase of the RIPT $(\mathrm{MCII}=0.097$ ) and non-sensitizing (reaction was only very slight erythema in 18/104 subjects with no persist oedema or infiltration reactions noted). The Cussons Baby Sensicare Intensive Soothing Cream was found to be very slightly irritating during the Induction Phase of the RIPT $(\mathrm{MCII}=0.078$ ) and non-sensitizing (reaction was only very slight erythema in $12 / 104$ subjects with no persist oedema or infiltration reactions noted). Results are summarised in Table 8.

Table 8. Overview of HRIPT results.

\begin{tabular}{|c|c|c|c|}
\hline Assessment & $\begin{array}{c}\text { Sensicare Gentle Hair \& Body } \\
\text { Wash }(N=104)\end{array}$ & $\begin{array}{l}\text { Sensicare } 24 \text { Hours Daily Moisturizing } \\
\text { Body Lotion }(N=104)\end{array}$ & $\begin{array}{l}\text { Sensicare Intensive Cream } \\
\qquad(N=104)\end{array}$ \\
\hline \multicolumn{4}{|c|}{ Induction phase of RIPT } \\
\hline MCII & 0.183 & 0.097 & 0.078 \\
\hline Irritating Potential & Slightly irritating & Very slightly irritating & Non irritating/negligible \\
\hline \multicolumn{4}{|c|}{$\begin{array}{c}\text { Challenge phase of HRIPT, ICDRG scores given for } 30 \text { minutes, } \\
24 \text { hours, } 48 \text { hours and } 72 \text { hours post patch removal }\end{array}$} \\
\hline Number with ICDRG Score 0 & $81,99,104,104$ & $86,96,100,102$ & $92,101,102,102$ \\
\hline Number with ICDRG Score 0.5 & $23,5,0,0$ & $18,8,4,2$ & $12,3,2,2$ \\
\hline Sensitizing Potential & Non sensitizing & Non sensitizing & Non sensitizing \\
\hline
\end{tabular}

ICDRG = International Contact Dermatitis Research Group; MCII = Mean Cumulative Irritation Index; HRIPT = Human Repeat Insult Patch Test. 


\section{Discussion}

The Skin Irritation Patch Test (48 h/96 h Exposure) in a panel of healthy subjects who have self-assessed sensitive, atopic skin is used to assess the primary skin irritation potential of Cussons Baby Sensicare products when applied cutaneously to subjects. The aim of this study was to substantiate the claims of "Dermatologically Tested and Approved", "Suitable for Sensitive Skin", "Suitable for Eczema Prone Skin" and "Paediatrician Approved" for each test material. Assessments were confirmed by a dermatologist and Paediatrician.

The test products were well tolerated during the study, producing low levels of irritation. All 96h test Products (Cussons Baby Sensicare 24 hours Daily Moisturizing Lotion and the Cussons Baby Sensicare Intensive Soothing Cream) were significantly lower than the positive control in terms of erythema, dryness and irritation level $(\mathrm{p}<0.05)$. The test product Cussons Baby Sensicare 24 hours Daily Moisturizing Lotion (020) was also significantly lower than the negative control, in terms of erythema and irritation levels. Cussons Baby Sensicare Gentle Hair \& Body Wash was significantly lower than the positive control in terms of erythema and irritation levels.

All test products can claim "Dermatologically Tested and Approved", "Suitable for Sensitive Skin", "Suitable for Eczema Prone Skin" and "Paediatrician Approved".

The human repeat insult patch test (HRIPT) is a standard cosmetic industry approach to testing a formulation's irritation and sensitization potential. The method used in this study was based on the Shelanski-Shelanski test method [7]. The induction phase evaluates the irritation potential of a product and the challenge phase (Phase II also known as the Elicitation Phase) evaluates the sensitization potential. A response during the challenge phase is normally an allergic one. The HRIPT evaluated the irritation after application of the products 15 times over a three week period. Irritation potential was also assessed in the cumulative skin patch test following 2 or 4 consecutive 23-hour patch application with assessment of reactions approximately 1 hour after each patch removal. The HRIPT was controlled with sterile water and included subjects with sensitive skin.

This study indicated that the Cussons Baby Sensicare products tested (Cussons Baby Sensicare Gentle Hair \& Body Wash, Cussons Baby Sensicare 24 hours Daily Moisturizing Lotion and the Cussons Baby Sensicare Intensive Soothing Cream) had a low irritation potential in adults with sensitive skin. There were no sensitization reactions in the HRIPT.

\section{Conclusion}

In conclusion, the Cussons Baby Sensicare range of products can be considered as low irritation potential and hypoallergenic on sensitive skin and suitable for eczema prone skin. 


\section{Acknowledgements}

The study was initiated and sponsored by PZ Cussons Indonesia. In addition, the test products were provided by Alba Science Ltd. and PT. Assetra Inno Medicos. We thank Ms. Marie Reynolds Bsc (Hons), SCS Dip. and Dr.rer.nat. Anna S. Ranti, Apt. for technical assistance.

\section{Conflicts of Interest}

The authors declare no conflicts of interest regarding the publication of this paper.

\section{References}

[1] Sarkar, R., Basu, S., Agrawal, R.K., et al. (2010) Skin Care for the Newborn. Indian Pediatrics, 47, 593-598. https://doi.org/10.1007/s13312-010-0132-0

[2] Fernandes, J.D., Machado, M.C. and Oliveira, N.Z. (2011) Children and Newborn Skin Care and Prevention. An Bras Dermatol, 86, 102-110. https://doi.org/10.1590/S0365-05962011000100014

[3] Zari, S.T. and Zari, T.A. (2015) A Review of Four Common Medicinal Plants Used to Treat Eczema. Journal of Medicinal Plants Research, 9, 702-711. https://doi.org/10.5897/JMPR2015.5831

[4] Vié, K., Cours-Darne, S., Vienne, M.P., et al. (2002) Modulating effects of oatmeal extracts in the sodium lauryl sulfate skin irritancy model. Skin Pharmacology and Applied Skin Physiology, 15, 120-124. https://doi.org/10.1159/000049399

[5] Viola P and Viola M. (2009) Virgin Olive Oil as a Fundamental Nutritional Component and Skin Protector. Clinics in Dermatology, 27, 159-165. https://doi.org/10.1016/j.clindermatol.2008.01.008

[6] Wollenweber, U. and Farwick, M. (2006) Application of Skin-Identical Ceramide 3 for Enhance Skin Moisturization and Smoothness: Latest Results. European Cosmetics. Special Issue, 1-5.

[7] Shelanski, H.A. and Shelanski, W.V. (1953) A New Technique of Human Patch Tests. Proceedings of the Scientific Section of the Toilet Goods Association, 19, 46-49. 